\title{
Epidemiological and Clinical Profiles of Chronic Kidney Disease Patients Presenting for Emergency Hemodialysis: A Five-Year Retrospective Study in Two Dialysis Centres in Cameroon
}

\author{
Denis Georges Teuwafeu ${ }^{1 *}$, Nlend Bah Joseph ${ }^{1,2,3}$, Maimouna Mahamat ${ }^{2,4}$, Nono Aristide ${ }^{2}$, \\ Kaze Folefack Francois ${ }^{3,4}$, Ashuntantang Gloria ${ }^{3,5}$ \\ ${ }^{1}$ Faculty of Health Sciences, University of Buea, Buea, Cameroon \\ ${ }^{2}$ General Hospital Yaoundé, Yaoundé, Cameroon \\ ${ }^{3}$ Yaoundé University Teaching Hospital, Yaoundé, Cameroon \\ ${ }^{4}$ Faculty of Medicine and Biomedical Sciences, University of Yaoundé 1, Yaoundé, Cameroon \\ ${ }^{5}$ Faculty of Health Sciences, University of Bamenda, Bamenda, Cameroon \\ Email: *d.teuwafeu@yahoo.com
}

How to cite this paper: Teuwafeu, D.G., Joseph, N.B., Mahamat, M., Aristide, N., Francois, K.F. and Gloria, A. (2022) Epidemiological and Clinical Profiles of Chronic Kidney Disease Patients Presenting for Emergency Hemodialysis: A Five-Year Retrospective Study in Two Dialysis Centres in Cameroon. Open Journal of Nephrology, $12,75-86$.

https://doi.org/10.4236/ojneph.2022.121007

Received: January 2, 2022

Accepted: February 25, 2022

Published: February 28, 2022

Copyright $\odot 2022$ by author(s) and Scientific Research Publishing Inc. This work is licensed under the Creative Commons Attribution International License (CC BY 4.0).

http://creativecommons.org/licenses/by/4.0/ (c) (i) Open Access

\begin{abstract}
Background: Late referral of Chronic Kidney Disease (CKD) patients requiring emergency hemodialysis (HD) for survival poses a serious threat to global health particularly in sub-Saharan Africa (SSA). Objective: Describe the epidemiological and clinical profiles of CKD patients starting HD in emergency. Methodology: This was a retrospective cross-sectional study. Files of patient files of CKD patients who underwent dialysis from January $1^{\text {st }}, 2016$ to December $31^{\text {st }}, 2020$ were reviewed at the HD centres of the two main hospitals of the Cameroon city capital, Yaoundé. We included all emergency HD for End Stage Renal Disease (ESRD). Socio-demographic and clinical data including past medical history, signs and symptoms at presentation and indications for emergency HD were recorded. Emergency HD was defined as a dialysis session performed in ESRD with a temporary vascular access. Data were analyzed using Statistical Package for Social Sciences (SPSS) software version 26 for Windows. Results: Out of 700 recorded CKD patients who started HD, 570 underwent an emergency HD, thus a prevalence of $81.43 \%$. We included 311 patients, $63.7 \%$ were males. The mean age was $47.05 \pm 15.60$ years ranging from 8 to 83 years with a modal age group of $40-59$ years. The most prevalent co morbidities were hypertension (66.2\%), diabetes mellitus (28.6\%) and HIV infection (10\%). The commonest presenting symptoms were
\end{abstract}


asthenia (68.2\%), lower limbs swelling (52.1\%) and anorexia (41.8\%) and the main clinical signs were high blood pressure (74.92\%), and pallor (60.5\%) and altered general state (55\%). The indications for emergency HD were dominated by uremic encephalopathy (33.4\%) and pulmonary oedema (25.7\%). Conclusion: More than eight out of ten CKD patients start emergency HD. Patients are mostly middle-aged adults with a male predominance. Hypertension and diabetes mellitus remain the most common co morbidities and uremic encephalopathy is by far the first indication for emergency HD.

\section{Keywords}

Epidemiology, Clinical Profile, Chronic Kidney Disease, Emergency

Hemodialysis, Cameroon

\section{Introduction}

According to Kidney Disease: Improving Global Outcomes (KDIGO) consensus conference in 2020, Chronic kidney disease (CKD) is defined as a GFR $<60$ $\mathrm{ml} / \mathrm{min}$ per $1.73 \mathrm{~m}^{2}$ or markers of kidney damage present for $>3$ months [1]. It is a major public health problem and was ranked as the $12^{\text {th }}$ cause of mortality worldwide in 2015 [2]. The global prevalence of CKD varies from $11 \%$ to $13 \%$ [3]. A meta-analysis conducted in 2018 estimated the pooled prevalence of CKD stage $1-5$ and $3-5$ in the African population at $15.8 \%$ and $4.6 \%$ respectively [4]. In Cameroon, the prevalence of CKD varies from $10.0 \%$ to $14.2 \%$ in urban areas [5].

End-Stage Renal Disease (ESRD) requiring kidney replacement therapy (KRT) is the common final pathway for CKD [6]. It has been projected that by 2030 the number of people requiring KRT worldwide will increase from 3.3 million to 5.4 million people with most of this increase in developing countries [7]. KRT can be planed or started in emergency. CKD poses a serious threat to global health [8], particularly in sub-Saharan Africa (SSA) with late presentation or referral of patients requiring emergency HD for survival [9]. In Cameroon, a single centre study revealed that $82.8 \%$ of $\mathrm{CKD}$ patients were referred late to the nephrologists with a consequent high rate of hospitalizations and emergency HD on first nephrology visit [10].

Emergency HD is burdened with high morbidity and mortality [11] [12] [13]. In 2015 a very high rate of emergency HD unplanned on a temporary vascular access was reported in Cameroon [14], showing that efforts and progress still need to be made in the follow up of CKD patients. However, late referred patients to nephrologists account in majority for emergency HD [15] and it is related to a poor cumulative survival rate within the first six months of dialysis initiation [16]. Therefore, this study aimed to determine the prevalence of emergency HD among CKD patients, describe the epidemiological and clinical characteristics of these patients and identify the indications for emergency HD. 


\section{Materials and Methods}

\subsection{Study Settings}

This was a retrospective cross-sectional study from January 2016 to December 2020 conducted in the HD units of the Yaoundé General Hospital (YGH) and the Yaoundé University Teaching Hospital (YUTH) in city capital of Cameroon. YGH is a 302 bedded tertiary public institution which serves as the main referral hospital for patients with kidney diseases in the region. Its HD unit has 11 functional Fresenius Medical Care dialysis machines at the time of this study (March to May 2021) with a staff made up of four nephrologists (one professor and three doctors), two assistant-nurses and 21 nurses. The unit is opened from Mondays to Sundays and runs for 24 hours each day. The YUTH is a teaching and referral hospital. Its HD unit has five functional Nipro Medical Care dialysis machines at the time of this study (March to May 2021) with a staff made up of two nephrologists, eight assistant-nurses and six nurses. The unit is opened from Mondays to Sundays and runs for 24 hours each day. There are four dialysis sessions per day lasting four hours each with one hour interval for decontamination after each session. Both facilities offer twice weekly dialysis of 04 hours per session. There is not insurance (health coverage) so the patients pay out of pocket. The study received administrative authorizations from both hospitals and an ethical approval from the Institutional Review Board of the Faculty of Health Sciences, University of Buea (IRB FHS-UB).

\subsection{Data Collection}

The study population involved all CKD patients without a history of KRT, who benefited from emergency HD session in both hospitals during the study period. Hard copy registries and medical records of all HD patients were retrieved. In each of the two selected HD units the total number of incident HD patients with CKD and those with dialysis initiation using a temporary vascular access were recorded. Medical files of incident HD patients with CKD were retained and the ones with dialysis initiation on a temporary vascular access were selected. Data were extracted for each patient

- Age and gender as recorded.

- Past medical history included documented history of Hypertension, Diabetes, viral serologies (Hepatitis C virus, Hepatitis B virus, HIV), and heart failure.

- Signs and symptoms on admission including general symptoms and systemic signs of uraemia or other associated conditions.

- Indications for emergency HD as reported in the selected medical files.

- Emergency HD was defined as a dialysis initiation performed in ESRD using a temporary vascular access indicated for life-threatening situations.

- Temporary vascular access was defined as a central venous catheter of short duration of Use.

- Incident HD was defined as HD initiation within the study period.

- High blood pressure was defined as a reported systolic blood pressure value 
$\geq 140 \mathrm{mmHg}$ and/or a diastolic blood pressure value $\geq 90 \mathrm{mmHg}$.

- High mean arterial pressure (MAP) was defined as a MAP value > 105 $\mathrm{mmHg}$.

- Incomplete file was defined as any medical file without information on the type of vascular access used for HD.

\subsection{Statistical Analysis}

Data were analyzed using Statistical Package for Social Sciences (SPSS) software version 26 for Windows and Microsoft EXCEL 2010. Categorical variables were represented as frequencies and percentages. Quantitative variables were represented as means and standard deviations.

\section{Results}

During the study period, out of a total of 700 incident HD patients with CKD, 570 underwent an emergency HD, thus, a prevalence of $81.43 \%$. Large number of patients excluded 249 patients from the study because of incomplete information in the file or missing files (Figure 1). We reviewed and included medical records of 311 emergency HD patients with CKD of which $61.41 \%(191 / 311)$ were from the YGH.

The mean age were $47.05 \pm 15.60$ years ranging from 8 to 83 years? Three patients out of four were aged less than 60 years, and the age range of $40-59$ represented $45 \%$ of the study population. Male patients were more prevalent and represented $63.7 \%$ (198/311) given ad female to male ratio of 1:1.75 (Table 1).

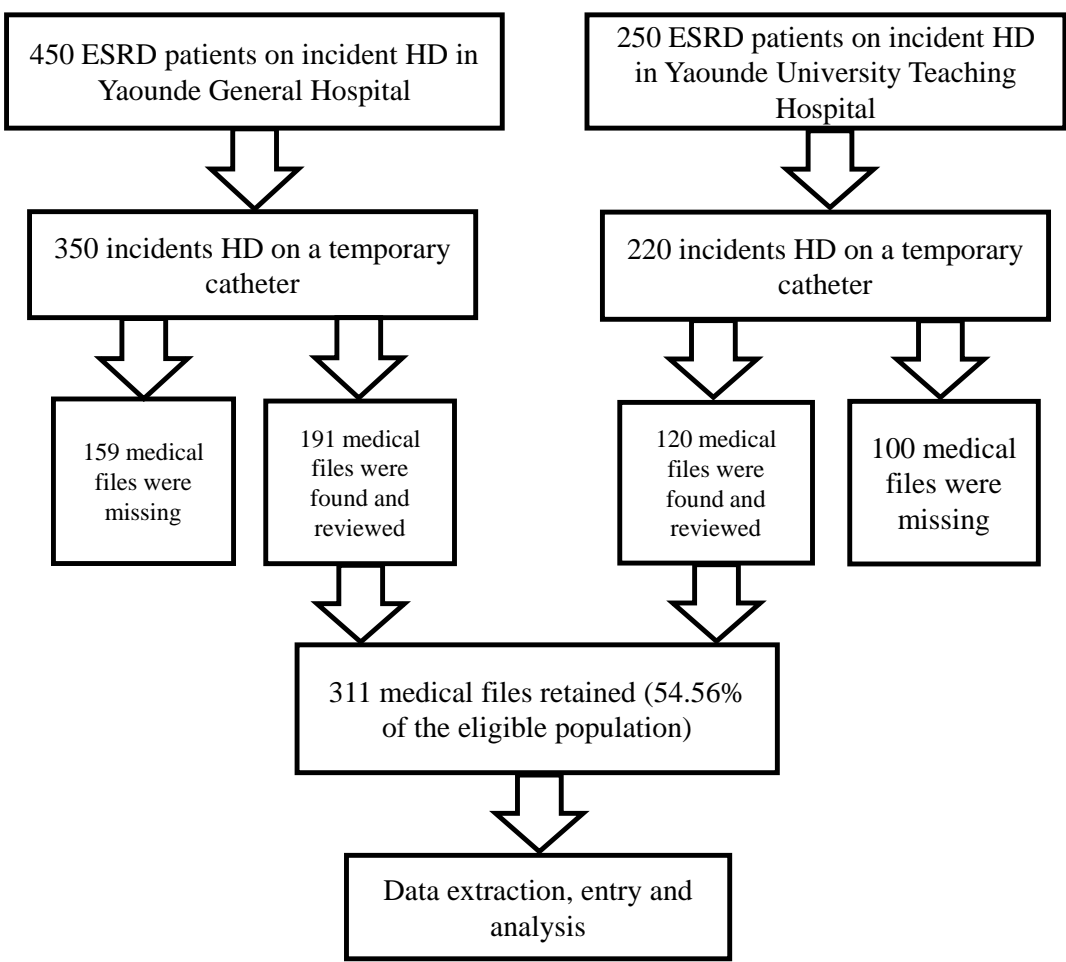

Figure 1. Selection of files. 
Table 1. Distribution of patients according to age and gender.

\begin{tabular}{ccc}
\hline Characteristics & Frequency $(\mathrm{N}=311)$ & Percentage $(/ 100)$ \\
\hline Age group (in years) & 19 & 6.1 \\
$<20$ & 78 & 25.1 \\
$20-39$ & 139 & 44.7 \\
$40-59$ & 75 & 24.1 \\
$\geq 60$ & & \\
Gender & 198 & 63.7 \\
Male & 113 & 36.3 \\
Female & & \\
\hline
\end{tabular}

Cardiovascular diseases were present in almost all patients $(97.9 \%)$ with hypertension and diabetes being the main co morbidities (hypertension: $66.2 \%$, diabetes mellitus: 28.6\%). Viral infections were less common and seen in 19\% of cases lead by human immunodeficiency virus infection (10\%), (Figure 2).

Non specific and general symptoms were common (74.6\%). All the systems were involved including musculoskeletal symptoms (63.34\%), neurological symptoms $(56.27 \%)$ and gastrointestinal symptoms (52.09\%). The main presenting symptoms were asthenia (68.2\%), lower limbs swelling (52.1\%), dyspnoea (40.2\%) and vomiting (37.9\%), (Table 2). On physical exams, 74.92\% (233/311) of patients had high blood pressure on admission and 63.67\% (198/311) of patients had high mean arterial pressure. Uremic fetor (47\%), flapping tremors, pericardial friction rub, uremic frost were the most frequent signs associated to uraemia. Anaemia was present in $60 \%$ of cases and signs of fluid overload were present in almost all the patient. The others clinical signs are shown in Figure 3.

In this study, the indications for emergency HD were varied and included uremic complication in $60 \%$ of patient with uremic encephalopathy being present in one out of three patients. Pulmonary oedema was seen in $25.7 \%$ patients. Metabolic acidosis indicated dialysis in $16.4 \%$ and severe hypertension was the indication in $10 \%$ of patients (Figure 4).

\section{Discussion}

The aim of this study was to determine the prevalence of emergency HD among CKD patients in YGH and YUTH, describe the epidemiological and clinical characteristics of these patients and identify the indications for emergency HD among these patients. We found an emergency HD prevalence of $81.43 \%$ among incident HD patients with CKD. The mean age of our patients was $47.05 \pm 15.60$ years with a male predominance. The main co morbidities were hypertension, diabetes mellitus and HIV infection. The commonest presenting symptoms were asthenia, lower limbs swelling and anorexia and the main clinical signs were high blood pressure, pallor and altered general state. The indications for emergency HD were dominated by uremic encephalopathy and pulmonary oedema. 


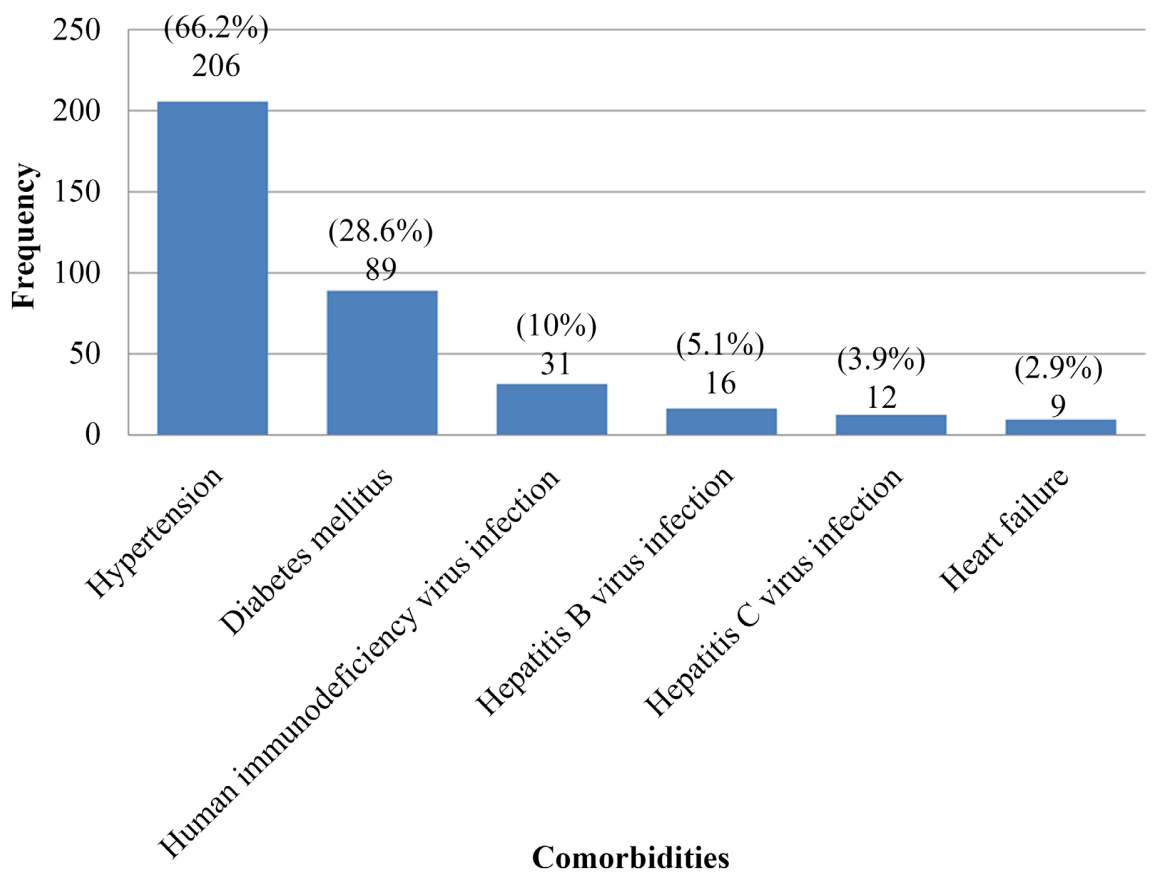

Figure 2. Comorbidities of the study population.

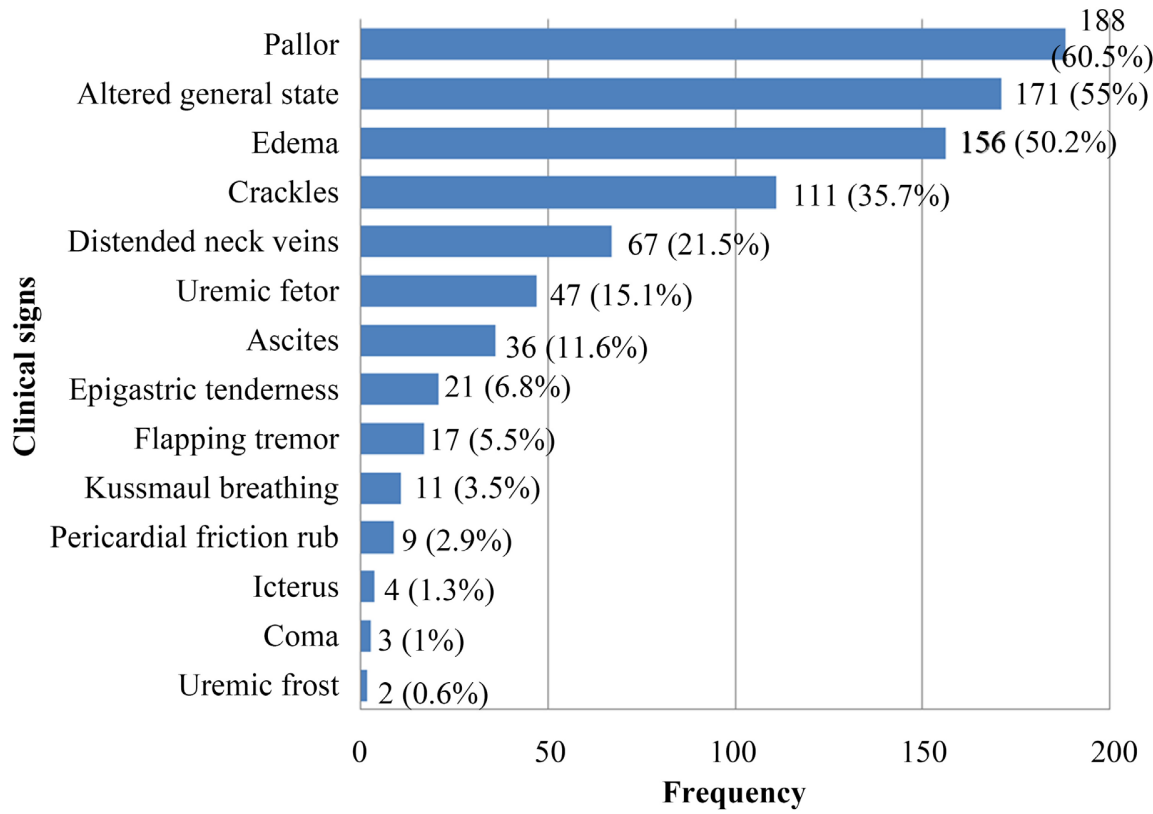

Figure 3. Distribution of patients according to clinical signs.

Table 2. Distribution of patients according to presenting symptoms.

\begin{tabular}{ccc}
\hline Symptoms & Frequency $(\mathrm{N}=311)$ & Percentage (100) \\
\hline General & 232 & 74.6 \\
Asthenia & 212 & 68.2 \\
Anorexia & 130 & 41.8 \\
Musculoskeletal & 197 & 63.34 \\
\hline
\end{tabular}




\section{Continued}

\begin{tabular}{|c|c|c|}
\hline Lower limbs swelling & 162 & 52.1 \\
\hline Muscle cramps & 41 & 13.2 \\
\hline Joint pain & 12 & 3.9 \\
\hline Back pain & 11 & 3.5 \\
\hline Muscle weakness & 10 & 3.2 \\
\hline Neurological & 175 & 56.27 \\
\hline Altered consciousness & 55 & 17.7 \\
\hline Insomnia & 51 & 16.4 \\
\hline Somnolence & 45 & 14.5 \\
\hline Headaches & 41 & 13.2 \\
\hline Blurred vision & 31 & 10.0 \\
\hline Confusion & 28 & 9.0 \\
\hline Slow ideation & 25 & 8.0 \\
\hline Convulsions & 19 & 6.1 \\
\hline Par aesthesia & 6 & 1.9 \\
\hline Gastrointestinal & 162 & 52.09 \\
\hline Vomiting & 118 & 37.9 \\
\hline Nausea & 63 & 20.3 \\
\hline Abdominal pain & 45 & 14.5 \\
\hline Diarrhoea & 28 & 9.0 \\
\hline Hiccups & 10 & 3.2 \\
\hline Gastrointestinal bleeding & 7 & 2.3 \\
\hline Respiratory & 149 & 47.91 \\
\hline Dyspnoea & 125 & 40.2 \\
\hline Cough & 69 & 22.2 \\
\hline Cardiovascular & 109 & 35.05 \\
\hline Orthopnea & 80 & 25.7 \\
\hline Chest pain & 23 & 7.4 \\
\hline Palpitations & 23 & 7.4 \\
\hline Urinary & 86 & 27.65 \\
\hline Anuria & 40 & 12.9 \\
\hline Oliguria & 33 & 10.6 \\
\hline Nycturia & 20 & 6.4 \\
\hline Polyuria & 5 & 1.6 \\
\hline In tegument & 25 & 8.04 \\
\hline Pruritus & 21 & 6.8 \\
\hline Skin rashes & 2 & 0.6 \\
\hline Bruising & 2 & 0.6 \\
\hline
\end{tabular}




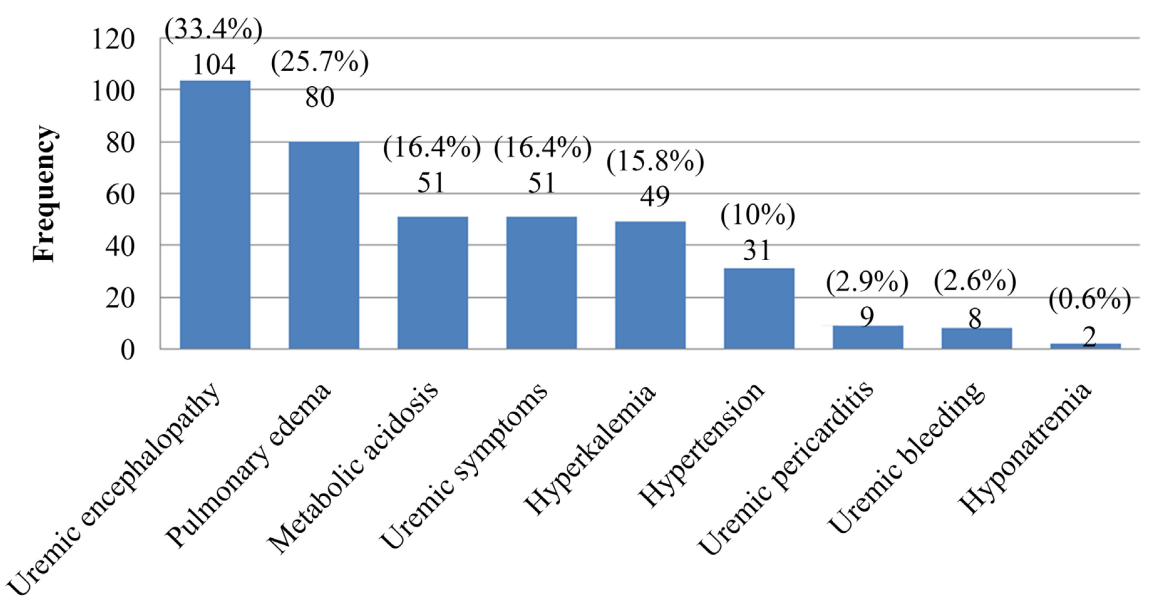

Indications for emergency hemodialysis

Figure 4. Indications for emergency hemodialysis of our study population.

In our study the prevalence of emergency HD among CKD patients was $81.43 \%$. This was likely similar to that found by Halle et al. in 2015 [14] who reported a prevalence of $88.3 \%$. However, our prevalence is higher than that of Diawara et al. in Senegal [9], who reported a prevalence of $40.68 \%$, this could be explained by the difference in financial policies between the two countries with the universal health coverage status established in Senegal. Also, Raffray et al. in France [17], and Brown et al. in Canada [13] reported a prevalence of $30.6 \%$ and $41.3 \%$ respectively. This very high rate of emergency HD in our study may be due to late presentation or referral of patients to the nephrologist in our study context, this was illustrated by Halle et al. in 2019 who reported a rate of $73.85 \%$ of late presentation to nephrologists in Cameroon, with a poor management prior to referral and a resultant worsening in the clinical and biological profiles related to the advanced stage of kidney impairment. Late presentation was defined as a GFR less than $30 \mathrm{ml} / \mathrm{min}$ meaning that more than 7 out of $10 \mathrm{CKD}$ patients in Cameroon present to the nephrologist at stage 4 or 5 of the disease [15]. Also, delay to the initiation of HD in our study context due to fear of dialysis, refusal to accept the kidney disease and financial constraints of some patients may explained the very high rate of emergency HD in our study.

The mean age of our patients was $47.05 \pm 15.60$ years with a modal age group of 40 - 59 years. This goes with the findings of Halle et al. [14] also in Cameroon who reported a mean age of $47.4 \pm 14.8$ years. Also, Diawara et al. [9] in Senegal reported a mean age of $46.39 \pm 17.13$ years with a modal age group of $40-59$ years which is likely similar to our findings. However, our patients seemed younger than those of Felah et al. [11] and Bensalem et al. [18] in Tunisia, who reported a mean age of $59 \pm 16$ years and 62 years respectively. This difference could be explained by the fact that life expectancy seems to be higher in Maghreb than in SSA; so, Maghrebians are likely to have a higher proportion of old age population than in our study context and old age ( $>60$ years) is a risk factors for ESRD [19] [20], thus explaining why their patients were older than ours. 
The male predominance with a sex ratio of $1.75: 1$ observed in our study is in agreement with many reports from developing countries [9] [14] [21] [22], and this could be explained by the predominance of CKD in men due to the fact that male gender is a risk factor for CKD as well as ESRD [19] [20] and also by the man financial power in Africa.

In our study, the most common co morbidities found in our patients were hypertension (66.2\%) and diabetes mellitus (28.6\%). This was consistent with previous studies from SSA [9] [18] [22]. This could be explained by the fact that both hypertension and diabetes mellitus are the main initiating factors for CKD and their incidence is rising in SSA.

The commonest symptoms in our study population were asthenia (68.2\%), lower limbs swelling (52.1\%), anorexia (41.8\%) and dyspnoea (40.2\%). These symptoms represent uremic manifestations due to the abnormally elevated blood urea level in CKD patients. Sylvanus et al. in Tanzania [23], reported dyspnoea as the most common presenting symptom in $45.9 \%$ of cases which is likely similar to the respective percentage found in our study.

The most common clinical signs in our study population were pallor $(60.5 \%)$, altered general state (55\%) and oedema (50.2\%). Diawaraet al. in Senegal [9], reported mucocutaneous pallor as the commonest clinical sign in $63.6 \%$ of cases and Konan et al. in Ivory Coast [21], reported oedema as the second most common clinical sign in $44.5 \%$ of cases. These findings are likely similar to ours, and this can be explained by the fact that in advanced CKD both the hormonal (erythropoietin production) and water and electrolytes balance functions of the kidneys are impaired accounting for the clinical anaemia and the salt and water retention (oedema) reported in our patients.

In our study, $74.92 \%$ of patients had a high blood pressure on admission. This was likely similar to the finding of the study conducted by Konan et al. in Ivory Coast [21], who reported high blood pressure as the main clinical sign in $78.33 \%$ of cases. This could be explained by the high proportion of known hypertensive patients in our study and also, by the vicious cycle existing between hypertension and CKD, where high blood pressure can be either the consequence or the causal mechanism of CKD.

The main indications for emergency hemodialysis in our patients were uremic encephalopathy (33.4\%) and pulmonary oedema (25.7\%). This was similar to the finding of Konan et al. in Ivory Coast [21], who reported uremic encephalopathy as the first indication for emergency HD in 33.5\% of cases. Diawara et al. in Senegal [9], reported poorly tolerated uraemia as the first indication for emergency HD in $50.47 \%$ of cases. Poorly tolerated uraemia was defined as blood urea level $>3 \mathrm{~g} / \mathrm{L}$ with clinical signs. This finding seems to be in line with our study where uraemia related complications all together represented $55.3 \%$ of indications for emergency HD. However, other SSA studies respectively Felah et al. in Tunisia [24] and Sylvanus et al. in Tanzania [23], reported hyperkalemia as the first indication for emergency $\mathrm{HD}$, this could be explained by the fact that in those studies cases of acute kidney injury (AKI) were included in their metho- 
dology, though AKI cases were represented in minority compared to CKD cases, it can explain the rise in the frequency of hyperkalemia accounting as the first indication for emergency HD in those respective studies.

\section{Study Limitations and Strengths}

Our study has some limitations. The retrospective nature of the study may have led to potential confounding information. Medical files of many patients were missed. Despite these limitations and giving the paucity of data on the issue in SSA, our study has a larger sample size and study period compared to the other related studies in SSA, which permitted us to generate stable estimates. Also, our results are informative and could serve as basis for further research on outcomes and associated factors to emergency HD in our setting.

\section{Conclusion}

This study reveals that in our setting more than eight out of ten CKD patients, still initiate HD in emergency. Those patients are mostly middle-aged male adults. Hypertension and diabetes mellitus remain the most common co morbidities. The commonest presenting symptom is asthenia and the main clinical sign is high blood pressure. Uremic encephalopathy is by far the first indication for

emergency HD. Further studies are needed to assess the spectrum in others HD centres at the national level.

\section{Conflicts of Interest}

The authors declare no conflicts of interest regarding the publication of this paper.

\section{References}

[1] Levey, A.S., Eckardt, K.-U., Dorman, N.M., Christiansen, S.L., Hoorn, E.J., Ingelfinger, J.R., et al. (2020) Nomenclature for Kidney Function and Disease: Report of a Kidney Disease: Improving Global Outcomes (KDIGO) Consensus Conference. Kidney International, 97, 1117-1129. https://doi.org/10.1016/j.kint.2020.02.010

[2] GBD 2015 Mortality and Causes of Death Collaborators (2016) Global, Regional, and National Life Expectancy, All-Cause Mortality, and Cause-Specific Mortality for 249 Causes of Death, 1980-2015: A Systematic Analysis for the Global Burden of Disease Study 2015. The Lancet, 388, 1459-1544. https://doi.org/10.1016/S0140-6736(16)31012-1

[3] Hill, N.R., Fatoba, S.T., Oke, J.L., Hirst, J.A., O’Callaghan, C.A., Lasserson, D.S., et al. (2016) Global Prevalence of Chronic Kidney Disease-A Systematic Review and Meta-Analysis. PLoS ONE, 11, Article ID: e0158765. https://doi.org/10.1371/journal.pone.0158765

[4] Kaze, A.D., Ilori, T., Jaar, B.G. and Echouffo-Tcheugui, J.B. (2018) Burden of Chronic Kidney Disease on the African Continent: A Systematic Review and Meta-Analysis. BMC Nephrology, 19, Article No. 125. https://doi.org/10.1186/s12882-018-0930-5

[5] Aseneh, J.B., Kemah, B.-L.A., Mabouna, S., Njang, M.E., Ekane, D.S.M. and Agbor, V.N. (2020) Chronic Kidney Disease in Cameroon: A Scoping Review. BMC Neph- 
rology, 21, Article No. 409. https://doi.org/10.1186/s12882-020-02072-5

[6] Halle, M.P., Ashuntantang, G., Kaze, F.F., et al. (2016) Fatal Outcomes among Patients on Maintenance Haemodialysis in Sub-Saharan Africa: A 10-Year Audit from the Douala General Hospital in Cameroon. BMC Nephrology, 17, Article No. 165. https://doi.org/10.1186/s12882-016-0377-5

[7] Bamgboye, E.L. (2016) The Challenges of ESRD Care in Developing Economies: Sub Saharan African Opportunities for Significant Improvement. Clinical Nephrology, 86, 18-22. https://doi.org/10.5414/CNP86S128

[8] Coresh, J. (2017) Update on the Burden of CKD. Journal of the American Society of Nephrology, 28, 1020-1022. https://doi.org/10.1681/ASN.2016121374

[9] Selly, D.M., Yaya, K., Moustapha, C.M., Tall, L.A., Maria, F., Coly, M., et al. (2020) L'Hémodialyse en Situation d'Urgence: Une Étude de 107 Cas au Centre d'Hémodialyse du CHR de Thiès (Sénégal). Health Sciences and Disease, 21, 5.

[10] Halle, M.P., Kengne, A.P. and Ashuntantang, G. (2009) Referral of Patients with Kidney Impairment for Specialist Care in a Developing Country of Sub-Saharan Africa. Renal Failure, 31, 341-348. https://doi.org/10.1080/08860220902882014

[11] Felah, E., Barbouch, S., Amiri, L., Hajji, N.M., Aoudia, R., Harzallah, A., et al. (2018) Hémodialyse en situation d'urgence: À propos de 115 cas. Néphrologie \& Thérapeutique, 14, 318. https://doi.org/10.1016/j.nephro.2018.07.158

[12] Felah, E., Barbouch, S., Najjar, M., Amiri, L., Agrebi, S., Ben, H.F., et al. (2020) Epidemiological Survey of a Population Undergoing Urgent Hemodialysis. Kidney International Reports, 5, S289. https://doi.org/10.1016/j.ekir.2020.02.750

[13] Brown, P.A., Akbari, A., Molnar, A.O., Taran, S., Bissonnette, J., Sood, M., et al. (2015) Factors Associated with Unplanned Dialysis Starts in Patients followed by Nephrologists: A Retropective Cohort Study. PLoS ONE, 10, Article ID: e0130080. https://doi.org/10.1371/journal.pone.0130080

[14] Halle, M.P., Takongue, C., Kengne, A.P., Kaze, F.F. and Ngu, K.B. (2015) Epidemiological Profile of Patients with End Stage Renal Disease in a Referral Hospital in Cameroon. BMC Nephrology, 16, Article No. 59. https://doi.org/10.1186/s12882-015-0044-2

[15] Halle, M.P., Nyongbella, J., Fouda, H., Balepna, J.Y., Kaze, F.F. and Ashuntantang, E.G. (2019) Factors Associated with Late Presentation of Patients with Chronic Kidney Disease in Nephrology Consultation in Cameroon-A Descriptive Cross-Sectional Study. Renal Failure, 41, 384-392. https://doi.org/10.1080/0886022X.2019.1595644

[16] Halle, M.P., Tsinga, L., Fottsoh, A.F., Kaze, F.F., Sone, M.A. and Ashuntantang, G. (2017) Does Timing of Nephrology Referral Influence Outcome among Patients on Maintenance Hemodialysis in Cameroon? Health Sciences and Disease, 18, 28-34.

[17] Raffray, M., Pladys, A., Gao, F., Couchoud, C., Bayat, S. and Vigneau, C. (2019) Étude du parcours de soins pré-dialyse des patients insuffisants rénaux chroniques terminaux démarrant la dialyse en urgence. Néphrologie \& Thérapeutique, 15, 378. https://doi.org/10.1016/j.nephro.2019.07.278

[18] Bensalem, M., Frih, A., Ghali, M., Elhmidi, K., Gazouini, N., Hamouda, M., et al. (2015) Hémodialyse en situation d'urgence: À propos de 114 cas. Néphrologie \& Thérapeutique, 11, 297-298. https://doi.org/10.1016/j.nephro.2015.07.093

[19] Dahnan, M., Assabri, A.M. and Khader, Y.S. (2019) Risk Factors for End-Stage Renal Failure among Patients on Hemodialysis in Aljomhory Hospital, Sa'adah Governorate, Yemen: Hospital-Based Case-Control Study. JMIR Public Health Surveill, 5, Article No. e14215. https://doi.org/10.2196/preprints.14215 
[20] Hsu, C., Iribarren, C., McCulloch, C.E., Darbinian, J. and Go, A.S. (2009) Risk Factors for End-Stage Renal Disease: 25-Year Follow-Up. Archives of Internal Medicine, 169, 342-350. https://doi.org/10.1001/archinternmed.2008.605

[21] Konan, S.D., Kissou, P.F., Guei, M.C., Diopoh, S.P., Aka, J.A. and Yao, K.H. (2020) First Emergency Hemodialysis Session at the Nephrology Department of the Teaching Hospital of Yopougon: About 146 Cases. Open Journal of Nephrology, 10, 338-347. https://doi.org/10.4236/ojneph.2020.104033

[22] Ba, B., Lemrabott, A.T., Faye, M., Faye, M., Mbengue, M., Diagne, S., et al. (2020) Hemodialysis in Emergency Situation in a Hemodialysis Center in Dakar: A Prospective Study about 81 Cases. Global Journal of Urology and Nephrology, 3, Article No. 19. https://doi.org/10.28933/gjun-2019-12-1605

[23] Sylvanus, E., Sawe, H.R., Muhanuzi, B., Mulesi, E., Mfinanga, J.A., Weber, E.J., et al. (2019) Profile and Outcome of Patients with Emergency Complications of Renal Failure Presenting to an Urban Emergency Department of a Tertiary Hospital in Tanzania. BMC Emergency Medicine, 19, Article No. 11. https://doi.org/10.1186/s12873-019-0229-2

[24] Felah, E., Samia, B., Mariem, H., Ben, A.S., Chargui, S., Trabelsi, R., et al. (2020) P1528. Epidemiological Survey of a Population Undergoing Urgent Hemodialysis. Nephrol Dial Transplant, 35, Article No. gfaa142.P1528.

https://doi.org/10.1093/ndt/gfaa142.P1528 